OPEN ACCESS

Edited by:

Hao Wang,

Tianjin Medical University General

Hospital, China

Reviewed by:

Lin Zhong,

Shanghai General Hospital, China

Bin Li,

Shanghai Jiao Tong University School

of Medicine, China

*Correspondence:

Xiao-Kang Li

ri-k@ncchd.go.jp

Wen-Zhi Guo

fccguowz@zzu.edu.cn

Specialty section:

This article was submitted to Alloimmunity and Transplantation,

a section of the journal

Frontiers in Immunology

Received: 28 January 2021

Accepted: 22 February 2021

Published: 06 April 2021

Citation:

Zheng Q, Zhang S, Guo W-Z and

Li X-K (2021) The Unique

Immunomodulatory Properties of MSC-Derived Exosomes in Organ

Transplantation

Front. Immunol. 12:659621. doi: 10.3389/fimmu.2021.659621

\section{The Unique Immunomodulatory Properties of MSC-Derived Exosomes in Organ Transplantation}

\author{
Qingyuan Zheng ${ }^{1}$, Shuijun Zhang ${ }^{1}$, Wen-Zhi Guo ${ }^{1 *}$ and Xiao-Kang $\mathrm{Li}^{1,2 *}$ \\ ${ }^{1}$ Department of Hepatobiliary and Pancreatic Surgery, The First Affiliated Hospital of Zhengzhou University, Zhengzhou, \\ China, ${ }^{2}$ Division of Transplantation Immunology, National Research Institute for Child Health and Development, Tokyo, Japan
}

Methods for suppressing the host immune system over the long term and improving transplantation tolerance remain a primary issue in organ transplantation. Cell therapy is an emerging therapeutic strategy for immunomodulation after transplantation. Mesenchymal stem cells (MSCs) are adult multipotent stem cells with wide differentiation potential and immunosuppressive properties, which are mostly used in regenerative medicine and immunomodulation. In addition, emerging research suggests that MSC-derived exosomes have the same therapeutic effects as MSCs in many diseases, while avoiding many of the risks associated with cell transplantation. Their unique immunomodulatory properties are particularly important in the immune system-overactive graft environment. In this paper, we review the effects of MSC-derived exosomes in the immune regulation mechanism after organ transplantation and graft-versus-host disease (GvHD) from various perspectives, including immunosuppression, influencing factors, anti-inflammatory properties, mediation of tissue repair and regeneration, and the induction of immune tolerance. At present, the great potential of MSC-derived exosomes in immunotherapy has attracted a great deal of attention. Furthermore, we discuss the latest insights on MSC-derived exosomes in organ transplantation and GvHD, especially its commercial production concepts, which aim to provide new strategies for improving the prognosis of organ transplantation patients.

\section{Keywords: immunomodulation, MSC-derived exosomes, immune tolerance, transplantation, GvHD}

\section{INTRODUCTION}

Organ transplantation is the most effective treatment for patients with end-stage disease, and it is one of the most noticeable and important achievements in the development of medicine in the 20th century (1). Although the short-term survival rate of allogeneic organ transplantation has been greatly improved, the development of methods to increase the long-term survival of transplanted organs remains a major challenge in clinical medicine. Currently, the combined application of immunosuppressant is the main method to prevent anti-rejection reaction after organ transplantation, but it is not sensitive to chronic rejection (2). Thus, the potential application of cell therapy in improving recipient tolerance to transplantation has attracted widespread interest. 
Mesenchymal stem cells (MSCs) are a group of self-renewing stem cells with broad differentiation potential, implantation and homing capabilities, and immunomodulatory effects; thus, they have been increasingly applied in clinical studies (3-5). MSCs derived from the development of early mesoderm and ectoderm, showed the expression of major histocompatibility complex I (MHC-I), CD90, CD105, and CD73, but did not express CD45, CD34, CD14, or CD11b (6). Under certain circumstances, they can be induced to differentiate into connective tissue, bone, cartilage, fat and bone marrow stromal cells. Some studies have confirmed that MSCs had an immunosuppressive effect, which can play an immunomodulatory role by inhibiting $\mathrm{T}$ cell proliferation, preventing $\mathrm{B}$ cell activation, affecting the differentiation, maturation, and function of dendritic cells (DCs) and interfering with the activation and maturation of antigen-presenting cells (APCs) (7-10). Besides, a study found that MSCs may inhibit IL-2-induced NK cell activity in vitro (11). Studies have shown that the paracrine function of MSCs is the key mechanism for the immune function. Exosomes are important molecules that play a role in the transmission of information and biological functions. This review systematically summarizes the mechanism, influencing factors and clinical applications of MSC immunosuppression, especially the research and prospects of MSC-derived exosomes in the field of organ transplantation and graft-versus-host disease (GvHD).

\section{THE IMMUNOSUPPRESSIVE EFFECT OF MSCs AND ITS MECHANISM}

MSCs have an immunomodulatory effect that influences all cells involved in the immune response (Figure 1). MSCs inhibit $\mathrm{T}$ cell activity, induce regulatory $\mathrm{T}$ cell activation, trigger cell apoptosis and arrest the cell cycle in the G0/G1 phase. Glennie et al. (12) found that the potential for the inhibition of B cell proliferation by MSCs is similar to that of T cells. It has been confirmed that MSCs can inhibit the proliferation of natural killer (NK) cells and interferon IFN- $\gamma$ stimulated by IL-2 or IL15(13). In summary, the MSCs inhibit the immune responses and effector cells of the memory cell, thereby modulating innate immunity and adaptive immunity. Furthermore, MSCs can increase the amounts of regulatory $\mathrm{T}$ cells (Tregs), regulatory $B$ cells (Bregs), and regulatory DCs (DCregs) - resulting in the loss of function of $\mathrm{T}$ cells - to regulate the immune function (14). BM-MSCs have also been proven to inhibit the proliferation and cytotoxicity of NK cells by changing the phenotype of NK cells and cell-to-cell contact $(15,16)$. In general, MSCs produce resistant cytokines, which directly inhibit the ongoing immune response and inhibit the proliferation of lymphocytes. Circulating hematopoietic cells actively home into the wall across the vascular endothelium of different organs and bone marrow; this is important for the host defense and repair functions (17). This depends on multiple molecular signals, including growth factors, chemical factors, and adhesion factors. The plastic adhesion properties of MSCs may have chemotactic functions (18). Similarly to other immune cells at sites of injury and inflammation, with the help of the homing ability, MSCs chemotactically transport to target organs, mediating anti-inflammatory response and tissue repair and regeneration. These functions represent a key feature that plays a role in regenerative medicine.

MSCs have effective immunomodulatory properties and antiinflammatory abilities, which produce extracellular vesicles, including exosomes, and a large number of cytokines and growth factors. The inhibition of the proliferation of $\mathrm{T}$ and $\mathrm{B}$ cells and the maturation of monocytes promotes the production of Tregs and M2 macrophages. Studies have shown that when the paracrine mechanism of MSCs is activated, they can directly secrete anti-inflammatory cytokines, such as indolamine 2,3dioxygenase (IDO), prostaglandin E2 (PGE2), nitric oxide (NO), HLA-G, transforming growth factor- $\beta$ (TGF- $\beta$ ), and vascular endothelial growth factor (VEGF) $(19,20)$. These cytokines affect the number of immune cells and achieve the effect of suppressing the immune response. Among them, PGE2 and IDO have a synergistic effect (21). Research by Cho et al. (22) showed that BM-MSCs can convert bone marrow-derived macrophages from M1 to M2, promote the proliferation of M2 macrophages, enhance the ability of macrophages to inhibit inflammation, and weaken their pro-inflammatory ability. The study by Vasandan et al. (23) was consistent with the above findings. MSCs produce soluble factors in response to inflammatory stimuli to induce the activation of the Treg, DCreg, and M2 populations in a variety of inflammatory diseases. Thus, even if the MSCs soon disappear in vivo, these cytokines can still suppress the immune level of the body for a long time (24).

According to several in vivo and in vitro studies, the immunosuppressive effect of MSCs is affected by many factors, such as different cell sources, administration methods and dosages, and the microenvironment created by the interaction with fibroblasts, endothelial cells, epithelial cells, and macrophages. For MSCs from different sources, although their proliferation and differentiation abilities are similar, they may show different specific phenotypes and immunomodulatory properties, resulting in differences in efficacy. Harman et al. (25) performed single-cell RNA sequencing (scRNA-seq) on primary equine MSCs that were collected from adipose tissue, bone marrow, and peripheral blood. They observed that transcriptional differences corresponded with phenotypic variance in cellular motility and the immune regulatory function (25). Meanwhile, the timing of administration, dosage and state of activation of MSCs has a great influence on the in vivo efficacy. In general, the dose of MSCs that is intravenously injected in mice is $5 \times 10^{7} / \mathrm{kg}$, while the clinical dose for humans is usually $1-2 \times 10^{6} / \mathrm{kg}(26)$. When BM-MSCs were intravenously administered preoperatively at doses of $0.5 \times$ $10^{6} / \mathrm{kg}$ and $1.0 \times 10^{6} / \mathrm{kg}$, combined with mycophenolate mofetil (MMF), to a mouse model of allogenic heart transplantation, the graft survival rates were different. Taken together, only the MSC-MMF combination of three different MSC-drug combinations led to a super-additive immunosuppressive effect. And the survival time of grafts in the low-dose group of BMMSCs was higher (27). A great deal of further experimentation is needed to investigate the dose-dependent effects. The 

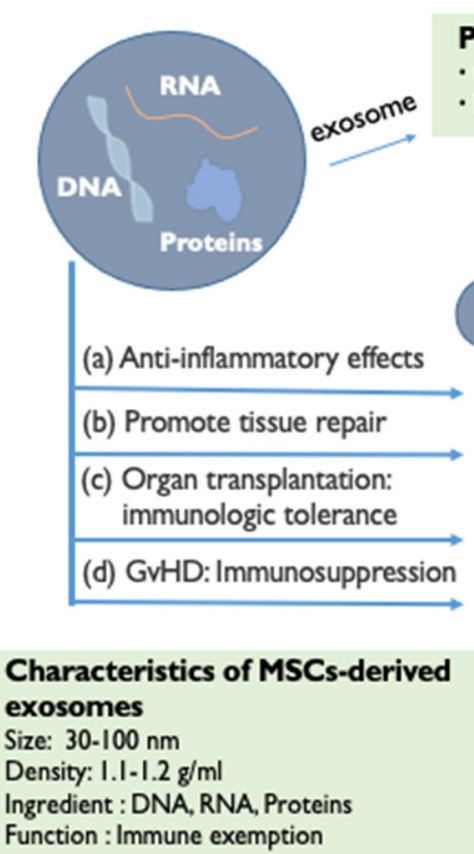

\section{Pretreatment method}

- Co-culture environment

- Lentivirus vector conversion
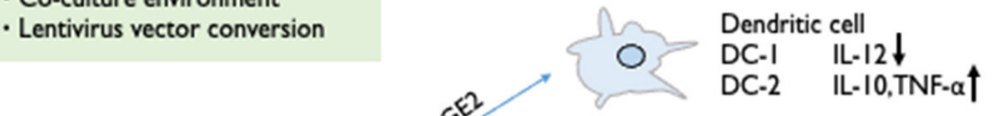

DC-I IL-12

DC-2 IL-10,TNF- $\alpha \uparrow$

Treg cell

Induce Treg $\uparrow$

NK cell

IL-2, IL-15, IFN- $-\downarrow$

Cytotoxicity $\downarrow$

B cell

Proliferation $\downarrow$

CXCR4,CXCR5,CXCR7\

Immune globulin $\downarrow$

T cell

Cyclin D, P27 $\uparrow$

Cell cycle arrest at G0

Proliferation $\downarrow$

CD25,CD38,CD6이

FIGURE 1 | The immunosuppressive effect of MSCs and MSC-derived exosomes. The immunomodulatory effects of MSCs can be largely attributed to paracrine factors (IDO, PGE2, NO, TGF- $\beta$, and exosome). By secreting soluble factors, the proliferation of T cells is inhibited (cell cycle arrest at G0), B cell activation is prevented (reduced proliferative capacity), NK cells are influenced (reduced cytotoxicity), and the differentiation and maturation of DC is affected. Through cell-to-cell contact, it can Tregs can be induced. MSC-derived exosomes are small vesicles of 30-100 nm in diameter, which are rich in important biomolecules such as DNA, RNA, and proteins. MSC-derived exosomes have the same immunosuppressive effect as MSCs. (a) Anti-inflammatory effects. (b) Promotion of tissue repair. (c) Organ transplantation: immunologic tolerance. (d) Immunosuppression in GvHD. The targeted pretreatment of exosomes is an important means of current biological treatment. The method of changing the co-culture environment, and the lentiviral vector transferring functional proteins or mRNA into exosomes, can pre-enhance the activity of exosomes to enhance efficacy.

immunosuppressive effects and mechanisms of MSCs derived from different tissues of the same species are also different. With the responder $\mathrm{T}$ lymphocyte population in mixed lymphocyte culture (MLC), the allogeneic and autologous MSCs induced a significant differentiation of $\mathrm{CD} 4^{+} \mathrm{T}$-cell subsets co-expressing CD25. However, only allogeneic MSCs favored an increase in cytotoxic T lymphocyte antigen-4+ populations. With respect to autologous MSCs, allogeneic MSCs may play a more effective suppressive activity (28). In particular, the positioning and migration of MSCs after in vivo injection are involved in the long-term tolerance of the graft by secreting soluble factors in close contact with the target site. At present, the combined use of multiple immunosuppressive agents causes different degrees of immunodeficiency, causing side effects, such as infection and malignant tumors, which are major problems after organ transplantation. However, whether MSCs can be used in combination with immunosuppressive agents remains to be verified. Will MSCs permanently alter the body's immune response mechanisms? We hypothesize that in a complex in vivo microenvironment, MSCs promote long-term tolerance of the graft and will also induce rejection. Therefore, an in-depth understanding of the interaction between MSCs and other cells is particularly important for the improvement of stem cell therapy in the future.

\section{MSC-DERIVED EXOSOMES}

Exosomes were first discovered in 1983 in the reticulocyte network. They are considered to be a physiological cystic structure of waste from the process of red blood cell development. They remove specific proteins during the maturation of reticulocytes. Exosomes includes DNA, mRNA, miRNA, and proteins and other important molecules. Active exosomes are secreted by a variety of cells of $30-100 \mathrm{~nm}$ in diameter, which have a lipid bilayer structure, and the distribution of Four transmembrane protein superfamilies; they carry and transport proteins, nucleic acids, lipids and other biologically active molecules (Figure 1) (29-32). In the process of transportation, exosomes not only maintain their biological activity but also can distribution of the transmembrane protein modify and process molecules, which plays an important role in the transduction of intercellular material and information (33). MSCs can tend to the injured site and perform the functions of tissue repair, wound healing, and immune regulation. Immunization exemptions are one reason for their high-profile in the field of organ transplantation (34). The paracrine effect is one of the important mechanisms for MSCs $(35,36)$. Bruno et al. (37) revealed that exosomes play an important role in the paracrine effect of MSCs. MSC-derived exosomes with cytokines and growth factors, lipid 
signals, mRNA, and miRNA regulatory biomolecules have a biological function or information transfer function $(38,39)$. They have similar functions to MSCs, including the promotion of tissue repair, immunosuppression, and neuroprotection. As a medium component of cell-to-cell communication, exosomes spread biological information between cells in the form of paracrine and remote secretion, and play an important regulatory role in physiological and pathological conditions.

More and more studies have shown that MSC-derived exosomes have the ability to affect the activity of immune cells, including T cells, B cells, NK cells, and macrophages. Studies have suggested that the therapeutic effect of exosomes is mediated by mRNA delivery. Many of these are involved in transcription regulation, proliferation, and immune regulation, indicating that they contribute to the induction of tissue regeneration (40). In addition, the function of exosomes is also affected by other molecules (such as proteins, lipids, enzymes, signal molecules) to exert their functional activities. These proteins are mainly involved in cell adhesion, membrane fusion and signal transduction (41). Those most common proteins are tetraspanin and integrin proteins (CD63, CD9, CD81, and CD82), which is crucial for cell adhesion. They are located on the surface of exosomes as markers $(42,43)$. Furthermore, the proteins involved in membrane fusion are Rab GTPases, annexins, and heat shock protein (HSP70 and HSP90) (43). Exosomes can interact with recipient cells by ligand-receptor binding or direct endocytosis. Exosome uptake by recipient cells is cell-specific. The interaction of surface molecules of exosomes is important for recipient cell targeting $(44,45)$. However, the complex microenvironment between different molecules or different cells causes the exosomes derived from MSC to be not equivalent. Exosomes of the same cell express different epitopes, indicating that there may be different subtypes of exosomes. Compared with BMSC-derived exosomes, AD-MSC contain up to 4-fold higher levels of enzymatically active neprilysin $(24,46)$. The molecules that synthesize exosomes actually depend on the cell type. MSCs are a major component of the tumor microenvironment (TME). MSC-derived exosomes will be altered when MSCs are cultured in TME. MSCs remodel the extracellular matrix, and tumorderived small vesicles may exert profound effects on tumor growth $(47,48)$. Hypoxia injury is one of the main causes of apoptosis and decreased $\beta$-cell function in islet grafts. In organ transplantation, a study found that huMSC-derived exosomes played an important role in hypoxic resistance, which could protect neonatal porcine islet cell clusters from hypoxia-induced dysfunction (49). The functions of different microenvironments are complex and changeable. In conclusion, we should further explore the interaction between different molecules on the surface or within exosomes.

\section{ANTI-INFLAMMATORY AND TISSUE REPAIR PROMOTING EFFECTS OF MSC-DERIVED EXOSOMES}

Recent studies have shown that MSCs will not directly implant and replace damaged tissues, and the exosomes secreted by MSCs are considered to be key cytokines with strong anti-inflammatory potential. A clinical study showed that MSC-derived exosomes may reduce the ability of peripheral blood mononuclear cells (PBMCs) to release proinflammatory cytokines in vivo. MSCderived exosomes upregulated IL-10 and TGF- $\beta 1$ from PBMCs, thereby promoting the proliferation and immunosuppression capacity of Tregs (50). Another study found that MSC-derived exosomes can reduce the neuroinflammation of autoimmune encephalomyelitis in mice and increase the number of Tregs to generate innate immunity (51). MSCs have been used for treating the inflammatory storm caused by severe pneumonia in COVID19 patients, MSC-derived exosomes are more convenient and superior, and are recommended for alternative treatments (52).

The exosomes obtained after IFN- $\gamma$ stimulation reduce the proliferation of PBMCs in vitro, reduce the pro-inflammatory factors and increase the immunosuppressive factor IDO $(53,54)$. In a study involving traumatic brain injury, Long et al. found that MSC-derived exosomes reduce the level of pro-inflammatory cytokines (55). Exosomes have been used as a treatment to reduce neuroinflammation after brain injury (56). Besides, MSC-derived exosomes have a special effect on the treatment of necrotizing enterocolitis (57-59) and bronchopulmonary dysplasia $(60,61)$. In a mouse model of bronchoalveolar dysplasia, MSC-derived exosomes can regulate the changes in the M1/M2 phenotype of macrophages to reduce the inflammatory damage caused by hyperoxia (62). Studies have found that Human Wharton's jelly mesenchymal stem cell (hWJ-MSC)-derived exosomes have antiinflammatory effects in perinatal brain injury (63). We therefore hope to explore the anti-inflammatory potential of exosomes derived from hWJ-MSCs in the treatment of brain injury. In vitro, exosomes affected microglia and reduced the LPS-stimulated release of pro-inflammatory cytokines. In vivo, the intranasal administration of hWJ-MSC-derived exosomes is an effective method for reducing neuroinflammation.

MSC-derived exosomes are small in size, and among the non-coding RNAs (miRNA and LncRNA) involved in immunosuppressive effects, the shorter miRNA is mostly involved in mRNA post-transcriptional regulation of gene expression levels, and thereby controls the key pathways of cell development and differentiation (64). Studies have found that in the brain damage caused by stroke, the increase of miR$133 \mathrm{~b}$ in exosomes released by bone marrow mesenchymal stem cells may be realized by the transfer of exosomes from MSCs to the parenchyma $(65,66)$. miR-133b transferred through the exosomes from MSCs into astrocytes may downregulate the expression of connective tissue growth factor (CTGF), reduce glial scarring, and facilitate axonal growth. Meanwhile, miR-133 downregulates the expression of RhoA protein, while inhibiting RhoA promotes the regeneration of the corticospinal tract after spinal cord injury (67). These studies have shown that MSCderived exosomes secrete mRNA to induce the regeneration of damaged tissues.

In an animal study of acute myocardial infarction, ligation of the left anterior descending artery (LAD) in rats induced cardiomyocyte apoptosis, and the immediate intravenous injection of human umbilical cord mesenchymal stem cells (hucMSC)-derived exosomes (400 $\mu \mathrm{g}$ of protein) could 
significantly improve cardiac contractility and reduce heart fibrosis. They hypothesized that hucMSC-derived exosomes may protect cardiomyocytes from apoptosis by regulating the expression of the $\mathrm{Bcl}-2$ family and promote the tube formation and migration of vascular endothelial cells (68). Exosomes secreted by hucMSCs protect cardiomyocytes from anoxia-reoxygenation injury (69). Similar studies are equally effective in mouse ischemia/reperfusion injury models (70). hucMSC-derived exosomes can alleviate $\mathrm{CCl}_{4}$-induced liver fibrosis, prevent cisplatin-induced renal oxidative stress and cell apoptosis, and enhance skin wound healing.

\section{RESEARCH AND EXPLORATION OF MSC-DERIVED EXOSOMES IN THE FIELD OF ORGAN TRANSPLANTATION}

Pre-infusion of different regulatory cells (including MSCs, Tregs and DCs) is currently a viable alternative therapy for transplant recipients. At present, the clinical application of MSCs in organ transplantation used to improve the prognosis of transplant recipients has broad prospects. However, efficiency is still the biggest concern in clinical research. Most clinicalstage MSC therapies have been unable to meet primary efficacy endpoints. This creates issues with practicality and feasibility (71). Although MSC-derived exosomes have similar functions to MSCs, the direct application of MSC-derived exosomes is not yet mature. Studies have proven the alloantigen presentation and immune regulation abilities of exosomes, which induced immune tolerance in a rat allograft model (72).

In allotransplantation, MHC antigen is the main foreign antigen that induces transplant rejection (73). The allograft survival rate mainly depends on the degree of human leukocyte antigen (HLA) type matching between the recipient and donor. Exosomes are MHC-bearing vesicles that are secreted by various cells. A study from the Institute of Transplantation of the University of Nantes in France found that exosomes express MHC-I and MHC-II $(74,75)$. The researchers found that injecting donor DC-derived exosomes both prolonged the survival time of rat heart allografts before and after transplantation. Interestingly, two injections of donor DCderived exosomes at 2 and 1 week, respectively, prior to heart allotransplantation did not induce tolerance to long-term graft survival. Thus, the researchers used LF15-0195 (a new type of immunosuppressant) with exosomes for short-term combination therapy, and found that it effectively prevented the maturation of DCs. Exosome/LF treatment prevented or significantly delayed the appearance of chronic rejection. MHC antigens from donor exosomes strongly suppressed the anti-donor proliferation response. Coincidentally, combined with rapamycin, donor exosomes from immature dendritic cells (imDex) can prolong the survival of cardiac allografts and induce specific allograft tolerance (76). These results suggest that the presentation of donor MHC antigens (from exosomes) in combination with immunosuppressive therapy induces a regulatory response that modulates allograft rejection and induces donor-specific allograft tolerance. It is noteworthy that data showed that the number of damaged blood vessels was significantly reduced in $60 \%$ of transplanted rats and that exosomes completely prevented chronic rejection in $40 \%$ of cases at 200 days after transplantation (74).

Immunosuppressants are the main treatment for avoiding immune rejection after organ transplantation. Exosomes combined with suboptimal doses of immunosuppressants may achieve specific allograft tolerance and long-term transplant survival (72). It is worth noting that it is difficult to achieve tolerance or long-term survival without the use of immunosuppressants. In a rat intestinal transplantation model, the intravenous infusion of exosomes from imDex $(20 \mu \mathrm{g})$ before transplantation could reduce the host's anti-donor cell response, induce the production of Tregs, and prolong the survival of allografts (77). The long-term use of immunosuppressants can increase the risk of infection, and it is important to determine the optimal dose or find alternative therapy. Tregs can protect allografts from immune rejection. Ma et al. (78) found that imDex combined with Tregs could induce immune tolerance in a rat liver transplantation model. Post-transplant liver samples were obtained for $\mathrm{HE}$ staining by researchers at 0 , 10, 35, and 100 days after transplantation. Interestingly, the imDex and Tregs treatment groups, respectively, showed a high number of inflammatory infiltrates and symptoms of chronic rejection (e.g., biliary atresia and cholestasis). However, there were no symptoms of chronic rejection in the co-processing group. At 100 days, the co-processing group of grafts showed regenerated hepatic fibrous tissue. Although the structure of the hepatic lobules is disordered, mononuclear cell infiltration is reduced. After liver transplantation, chronic rejection leads to structural disorder of hepatic lobules and tissue fibrosis. The immunomodulatory effects of MSC-derived exosomes and their promotion of angiogenesis and tissue repair effectively alleviated the progress of the pathological process. Thus, we confirm that MSC-derived exosomes can be an important foundation for the treatment of chronic rejection of the field of liver transplantation. Co-treatment reduced rejection and helped the recipient liver regenerate after undergoing slight acute rejection (78).

During transplantation, graft injury caused by cold ischemia, organ preservation, and reperfusion has always been a matter of concern. After ischemic injury, the graft will undergo a second blow of reperfusion injury as blood flow opens up. In an experiment using a rat model of kidney donation after circulatory death, the researchers used Belzer solution (BS) and BS supplemented with MSC-derived exosomes to compare renal perfusion injury. During cold organ perfusion $(4 \mathrm{~h})$, the signs of kidney damage were significantly less severe in DCD kidneys treated with MSC-derived exosomes (79). Ischemia reperfusion injury (IRI) is an important cause of liver failure after liver resection and early non-immunological inactivation after liver transplantation. It also increases the chance of acute and chronic rejection of the transplanted organ and leads to late immunological inactivation (80). Preconditioning of graft perfusion with MSCs and MSC-derived exosomes before transplantation may be an effective method for limiting ischemiareperfusion injury. Using a normothermic hypoxic rat liver perfusion model, Rigo et al. (81) perfused the graft for $4 \mathrm{~h}$ and 
delivered extracellular vesicles derived from human hepatic stemlike cells (HLSCs), and found that the levels of hepatocyte damage and hepatocyte lysis markers in the lavage fluid were reduced. This effect has also been verified in the lung (82) and heart (83). Although they did not use MSC-derived exosomes, we could also observe that using exosomes would be very likely to limit the graft damage caused by ischemia-reperfusion before and after transplantation (84-87).

In addition, in heart transplantation, a study found a new biomarker method in which donor heart exosomal signals are monitored to understand the intensity of immune rejection after transplantation. We can use exosomes from the recipient's blood or urine for functional monitoring of allograft dysfunction and rejection. This is an effective way to reduce the pain of invasive biopsies (88). Studies have confirmed that exosomes can be used as biomarkers for tolerance monitoring in kidney (89), heart (90), liver (91), islet (92), and lung (93) transplantation. Furthermore, in post-myocardial infarction inflammation, hucMSC-derived exosomes increased the density of infarct myofibroblasts, reduced inflammation, and promoted the differentiation of fibroblasts into myofibroblasts inflammation in vitro. Researchers hypothesize that human MSC-derived exosomes may have a cardioprotective effect. MSCs-secretions improve the donor heart function following ex vivo cold storage (94). In a porcine model of myocardial infarction subjected to intravenous bolus injection, myocardial infarction measured at 7 and 28 days significantly reduced the infarct size (30-40\%) (95). This opens up new ideas for fibrosis caused by chronic rejection after organ transplantation. Jiang et al. (70) also found MSC-derived exosomes can reduce oxidative stress, the inhibition of hepatic apoptosis, and reduced $\mathrm{CCl}_{4}$ induced liver fibrosis. In engrafted liver mouse models, a single systemic administration of human MSC-derived exosomes (16 $\mathrm{mg} / \mathrm{kg}$ ) effectively rescued the recipient mice from $\mathrm{CCl}_{4}$-induced liver failure (96). IDO-BMSC-derived exosomes can be used to improve immune tolerance and prolong survival of heart allotransplantation (97). Given the few existing studies on MSCderived exosomes in the transplantation field, this will be a new research direction. Combined with the previous statement, MSCderived exosomes are beneficial for tolerance induction in organ transplantation. Considering its characteristics as a drug carrier, the use of exosomes will undoubtedly become a direction of scientific and technological development in the field of organ transplantation (98).

Furthermore, in numerous studies exploring the roles of exosomes in tumor immunity, exosomes have a dual function of adjustment on tumor cell proliferation (99, 100). Following the injection of MSC-derived exosomes into a mouse model of liver cancer, the anti-tumor miR-122 and other secreted biological molecules not only effectively inhibited tumor growth, but also significantly increased the antitumor efficacy of sorafenib against hepatocellular carcinoma (101). Another study found that MiR-199a-modified exosomes from AD-MSCs improved hepatocellular carcinoma chemosensitivity through the mTOR pathway (102). Multiple studies have shown that exosomes combined with immunosuppressants or targeted chemotherapeutic agents are effective in the treatment of chronic rejection or cancer. However, the effect of direct infusion of miRNA is easy to degrade. The author believes that MSC-derived exosomes can be used as carriers for drug and molecular delivery, and that pretreatment of target effect miRNA can become a consensus for disease treatment. If pretreated exosomes are used to enhance the sensitivity of chemotherapeutic agents in reducedtime treatment before liver transplantation for patients with liver cancer, it will effectively reduce the perioperative time and improve the patient prognosis. These studies have provided new ideas for the adjuvant treatment of liver cancer patients with liver transplantation $(101,102)$.

After reviewing the literature, we retrieved 93 studies of exosomes on www.clinicaltrials.gov, including 3 MSC-derived exosomes clinical trials involving acute ischemic stroke and ophthalmic diseases (103). They have also been reported to have therapeutic effects on acute and chronic kidney disease in animal models. Many efforts have been made to prove that MSC and MSC-derived exosomes can produce similar therapeutic benefits in various disease models (24). Clinical application showed the feasibility of exosomes. Current research focuses on preconditioning the graft before transplantation and preventing ischemia/reperfusion injury to improve the viability of transplanted organs $(104,105)$. In large animal experiments, we can better understand the biological and functional characteristics of MSC-derived exosomes and define the acceptance in allotransplantation. However, there is no studies have been conducted on the application of MSC-derived exosomes in large animal transplantation models. In pig models of traumatic brain injury and hemorrhagic shock, early treatment with a single dose of exosomes provided neuroprotective effects and improved Blood brain barrier integrity (106108). In fact, using large animals (pigs or monkeys) is more convincing than small animal models. The advantages of large animal experiments include the complexity of the disease, effective cell dose, cell survival rate after transplantation, and tissue inflammation and immune response associated with transplantation $(109,110)$. Therefore, we need to invest a lot of energy to study the role of MSC-derived exosomes in large animal transplantation models before clinical application. Xenotransplantation is the development direction of organ transplantation (111). However, there is no application of MSC-derived exosomes in xenotransplantation. If MSC-derived exosomes can reduce the risk of rejection of xenotransplantation, it will be a milestone breakthrough. We boldly speculate that with the continuous development of research, the application of MSCderived exosomes in organ transplantation will produce better and better results.

\section{MSC-DERIVED EXOSOMES AND GvHD}

MSCs were introduced as a treatment strategy for acute GvHD by Le Blanc et al. (112). The application of MSCs in the treatment of GvHD is summarized in Table 1 (118). As described above, MSC-derived exosomes play the same role as MSCs. In GvHD, a study published in 2014, which describes the first human case in which MSC-derived exosomes were successfully used to treat 
TABLE 1 | The application of MSCs in GVHD.

\begin{tabular}{|c|c|c|c|c|c|c|}
\hline Clinical research & $\begin{array}{l}\text { Source of } \\
\text { MSCs }\end{array}$ & Injection-method & Injection dose & Type of Study & Research results & References \\
\hline $\begin{array}{l}\text { CBT combined } \\
\text { MSCs (MSC-CBT) }\end{array}$ & BM-MSCs & $\begin{array}{l}\text { Intramedullary } \\
\text { injection }\end{array}$ & / & Phase I trial & $\begin{array}{l}\text { Co-transplantation of MSCs may prevent } \\
\text { GVHD with no inhibition of engraftment }\end{array}$ & (113) \\
\hline $\begin{array}{l}\text { CBT combined } \\
\text { MSCs (MSC-CBT) }\end{array}$ & BM-MSCs & $\begin{array}{l}\text { Intramedullary } \\
\text { injection }\end{array}$ & $0.5 \times 10^{6} / \mathrm{kg}$ & Phase I trial & $\begin{array}{l}\text { The safety of CBT combined with } \\
\text { intrabone marrow injection of MSCs }\end{array}$ & $(114)$ \\
\hline $\begin{array}{l}\text { GvHD after HSC } \\
\text { transplantation }\end{array}$ & AT-MSCs & / & $\begin{array}{l}1 \times 10^{6} / \mathrm{kg}, 3 \times \\
10^{6} / \mathrm{kg}\end{array}$ & Phase $1 / / I$ trial & $\begin{array}{l}\text { AT-MSCs, in combination with } \\
\text { immunosuppressive therapy, may be } \\
\text { considered feasible and safe }\end{array}$ & (115) \\
\hline $\begin{array}{l}\text { Akt1-MSCs } \\
\text { Ameliorates Acute } \\
\text { Liver GVHD. }\end{array}$ & BM-MSCs & I & / & $\begin{array}{l}\text { Prospective } \\
\text { controlled study }\end{array}$ & $\begin{array}{l}\text { BM-MSCs genetically modified with Akt1 } \\
\text { have a survival advantage and an } \\
\text { enhanced immunomodulatory function }\end{array}$ & $(116)$ \\
\hline $\begin{array}{l}\text { Steroid-refractory } \\
\text { GvHD after HSC } \\
\text { transplantation }\end{array}$ & BM-MSCs & Intravenous injection & $\begin{array}{l}6.81 \times 10^{6} / \mathrm{kg} \\
(\text { range, } 0.98-29.78 \\
\left.\times 10^{6} / \mathrm{kg}\right)\end{array}$ & $\begin{array}{l}\text { Multi-center } \\
\text { retrospective } \\
\text { study }\end{array}$ & $\begin{array}{l}\text { This therapeutic modality is safe and } \\
\text { should be considered for steroid-refractory } \\
\text { aGvHD }\end{array}$ & $(117)$ \\
\hline
\end{tabular}

CBT, cord blood transplantation; MSCs-CBT, CBT combined MSCs; HSC, haploid hematopoietic stem cell; AT-MSCs, adipose tissue-derived mesenchymal stromal cells; Akt1-MSCs, BM-MSCs genetically modified with AKT1; aGvHD, acute graft-versus-host disease.

graft-versus-host disease, seems to indicate that it is feasible to use MSCs as a therapeutic agent for the alternative therapy of various diseases (119). Lai et al. (120) injected MSC-derived exosomes into a GvHD model; this significantly inhibited the activity of Th17 and Treg cells, and reduced immune rejection and pathological damage. MSC-derived exosomes effectively prolonged the survival of chronic GvHD mice and diminished the clinical and pathological scores of chronic GvHD (120). In the same study, in a GvHD model induced by the injection of human peripheral blood mononuclear cells into irradiated mice, MSC-derived exosomes could alleviate the symptoms of GvHD and improve the survival rate. MSC-derived exosomes promoted the production of Tregs in vivo and in vitro through APC-mediated pathways (121). Interestingly, in the mouse GvHD model, human BM-MSCs were injected intravenously into the mouse 3 days after the operation. When the BMMSCs undergo macrophage phagocytosis, inflammatory M1 macrophages were functionally attenuated with a concomitant shift toward alternatively activated M2 state. The effector mechanisms of immunosuppression are activated in BM-MSCs, increasing the metabolic conversion efficiency of macrophages and resulting in a large reduction in IDO spleen and lung inflammatory infiltration (23). MSC paracrine factors can cause immunosuppression for a long time. Extracellular vesicles derived from mesenchymal stem cells (MSC-EVs) prevented fibrosis in a sclerodermatous chronic GvHD mouse model by suppressing the activation of macrophages and the B cell immune response (122). The application of MSC-derived exosomes in GvHD and transplantation is summarized in Table 2.

\section{GENE EDITING OF MSC-DERIVED EXOSOMES}

MSC-derived exosomes have been confirmed to play a therapeutic role in a variety of disease models. If a method can be found for enhancing the efficacy of exosomes before infusion therapy, for example (e.g., gene-editing, tumor targeted delivery), it may expand the numbers of patients in a good prognosis (Figure 1) $(124,125)$. Different sources of MSCs affect the characteristics of the secreted exosomes; however, the MSCs are changed by changes in the external microenvironment. Can pretreatment with MSCs enhance the activity of exosomes to increase their efficacy? Studies have found that under a hypoxic environment, and after some cytokines and chemicals change the state of MSCs, their immune regulation function, including immune suppression and the ability to promote tissue and blood vessel regeneration, change (126). Under a hypoxic environment, the proliferation ability of BM-MSCs decreases, while adipose mesenchymal stem cells (AD-MSCs) increase. The gene and cell surface of MSCs can also be modified to enhance the therapeutic effect of exosomes. It has been reported that directly or indirectly increasing the activity of exosome pretreatment may be used to maximize the therapeutic potential of MSC-derived exosomes. For example, Ma et al. found that exosomes released by Akt-overexpressing MSCs showed beneficial effects in cardioprotection and angiogenesis, and the cardiac function of animals treated with Akt-Exo was significantly improved. The expression of platelet-derived growth factor D (PDGF-D) in Akt-Exo was significantly upregulated. In addition, Akt-Exo also significantly promotes the proliferation and migration of vascular endothelial cells for the formation of the tubular structure of blood vessels, tube-like structure formation in vitro and blood vessel formation in vivo (67). Regarding the application in the field of organ transplantation, Wen et al. modified human bone marrow mesenchymal stem cells so that their overexpression could inhibit the expression of fatty acid synthetase (Fas) interfering RNA and inhibit the expression of miR-375 RNA. The source and culture conditions of MSCs affected the function of exosomes. Exosomes cocultured with PBMCs were transferred into an rat model of islet transplantation, downregulated Fas and miR-375 of islets. Then, by inhibiting the proliferation of PBMCs and enhancing Treg cell function, it exhibits an immunoregulatory function that 
TABLE 2 | The application of MSC-derived exosomes in GvHD and transplantation.

\begin{tabular}{|c|c|c|c|c|c|c|}
\hline Clinical research & Source of exo & Injection-methods & Injection dose & $\begin{array}{l}\text { Type of } \\
\text { Study }\end{array}$ & Research results & References \\
\hline An cGVHD mouse model & $\begin{array}{l}\text { MSCs-exo/Fib- } \\
\text { exo }\end{array}$ & Tail vein injection & $\begin{array}{l}\text { Once a week for } \\
6 \text { weeks }\end{array}$ & $\begin{array}{l}\text { Preclinical } \\
\text { studies }\end{array}$ & $\begin{array}{l}\text { MSCs-exo could improve the survival and } \\
\text { ameliorate the pathologic damage of } \\
\text { cGVHD by suppressing Th17 cells and } \\
\text { inducing Treg }\end{array}$ & (120) \\
\hline $\begin{array}{l}\text { MSC-ex secreted by } \\
\text { MSCs stimulated by } \\
\text { different cytokines }\end{array}$ & huc-MSCs & / & / & $\begin{array}{l}\text { Preclinical } \\
\text { studies }\end{array}$ & $\begin{array}{l}\text { TGF- } \beta \text { combined with IFN- } \gamma \text { exosome } \\
\text { more effectively promoted the } \\
\text { transformation of mononuclear cells to } \\
\text { Tregs, IDO may play an important role }\end{array}$ & (54) \\
\hline An aGVHD mouse model & BM-MSCs & Intravenous injection & / & $\begin{array}{l}\text { Preclinical } \\
\text { studies }\end{array}$ & $\begin{array}{l}\text { The amelioration of aGVHD by therapeutic } \\
\text { infusion of BM-MSC-derived EVs is } \\
\text { associated with the preservation of } \\
\text { circulating naive T cells }\end{array}$ & (123) \\
\hline $\begin{array}{l}\text { The lethal chimeric } \\
\text { human-SCID mouse } \\
\text { model of GVHD }\end{array}$ & $\begin{array}{l}\text { MSCs-exo were } \\
\text { incubated with } \\
\text { mouse spleen } \\
\text { CD4 }{ }^{+} \mathrm{T} \text { cells }\end{array}$ & / & / & $\begin{array}{l}\text { Preclinical } \\
\text { studies }\end{array}$ & $\begin{array}{l}\text { MSC exosome enhanced Treg production } \\
\text { in vitro and in vivo through an } \\
\text { APC-mediated pathway. }\end{array}$ & $(121)$ \\
\hline $\begin{array}{l}\text { A mouse hepatic I/R } \\
\text { model }\end{array}$ & MSCs-Heps-exo & Tail vein injection & $100 \mu \mathrm{g}$ & $\begin{array}{l}\text { Preclinical } \\
\text { studies }\end{array}$ & $\begin{array}{l}\text { In vivo, MSC-Heps-Exo effectively relieve } \\
\text { hepatic I/R damage, reduce hepatocyte } \\
\text { apoptosis }\end{array}$ & (86) \\
\hline $\begin{array}{l}\text { A mouse hepatic l/R } \\
\text { model }\end{array}$ & UC-MSCs & Tail vein injection & / & $\begin{array}{l}\text { Preclinical } \\
\text { studies }\end{array}$ & $\begin{array}{l}\text { MiR-20a-containing exosomes from } \\
\text { umbilical cord mesenchymal stem cells } \\
\text { alleviates liver ischemia/reperfusion injury }\end{array}$ & (85) \\
\hline $\begin{array}{l}\text { Mouse models of } \\
\mathrm{CCl}_{4} \text {-induced ALI/CLI }\end{array}$ & hucMSCs-exo & Tail vein injection & $\begin{array}{l}6 \times 10^{10} \\
\text { particles } / \mathrm{kg}, 1.2 \\
\times 10^{11} \\
\text { particles } / \mathrm{kg}, 2.4 \\
\times 10^{11} \\
\text { particles } / \mathrm{kg}\end{array}$ & $\begin{array}{l}\text { Preclinical } \\
\text { studies }\end{array}$ & $\begin{array}{l}\text { hucMSC-Ex alleviated CCl4-induced } \\
\text { acute liver injury and liver fibrosis and } \\
\text { restrained the growth of liver tumors }\end{array}$ & (70) \\
\hline $\begin{array}{l}\text { Rats heart transplants } \\
\text { model }\end{array}$ & IDO-BMSCs & Intravenous injection & $800 \mathrm{mg} / \mathrm{ml}$ & $\begin{array}{l}\text { Preclinical } \\
\text { studies }\end{array}$ & $\begin{array}{l}\text { Exosomes derived from IDO-BMSCs can } \\
\text { be used to promote immunotolerance and } \\
\text { prolong the survival of cardiac allografts }\end{array}$ & (97) \\
\hline An rat IRI model & $\begin{array}{l}\text { BMSCs-exo/Fib- } \\
\text { exo }\end{array}$ & Intravenous injection & / & $\begin{array}{l}\text { Preclinical } \\
\text { studies }\end{array}$ & $\begin{array}{l}\text { Rat BM-MSC-derived exosome protects } \\
\text { against ischemia reperfusion injury with } \\
\text { decreased inflammatory response and } \\
\text { apoptosis in rats. }\end{array}$ & (84) \\
\hline $\begin{array}{l}\text { An IRR-induced ALL } \\
\text { model }\end{array}$ & BMSCs-exo & Intravenous injection & $5-10 \mu \mathrm{g}$ & $\begin{array}{l}\text { Preclinical } \\
\text { studies }\end{array}$ & $\begin{array}{l}\text { MSC-derived exosomes provide } \\
\text { protection similar to that of MSCs against } \\
\text { IIR-induced ALI via inhibition of } \\
\text { TLR4/NF-KB signaling }\end{array}$ & (87) \\
\hline
\end{tabular}

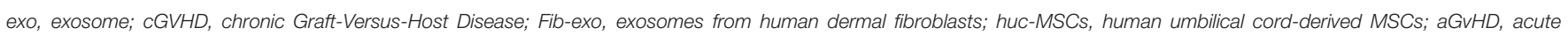

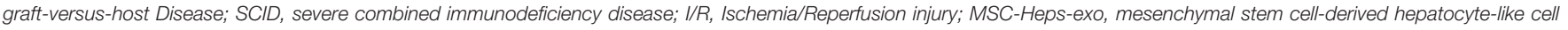
exosomes; $\mathrm{CCl}_{4}$, carbon tetrachloride; ALI, acute liver injury; CLI, chronic liver injury; IDO, indoleamine 2;3-dioxygenase; ALI, acute lung injury; IIR, intestinal ischemia-reperfusion.

significantly improves immune tolerance after pancreatic islet transplantation $(127,128)$.

Given the ability of MSCs to return to the nest site of injury, they may serve as a good carrier for MSC-derived exosomes. In order to increase the effect of exosomes, we aim to explore the exosomes synthesis/secretion pathway of MSCs. By gene editing or changing the microenvironment of MSCs, we hope to increase the number and purity of exosomes after pretreatment of MSCs, which can deliver accurate and large amounts of MSC-derived exosomes to target tissues effect. For example, we can preserve 
the original function of anti-inflammatory and tissue repair of exosomes. At the same time, we edit and introduce shRNA or miRNA with disease treatment effects into MSC-derived exosomes, so that exosomes could increase the gene therapy effect of specific nucleic acids. The author believes that in future clinical applications, especially for chronic rejection after organ transplantation, it will be possible to use MSC-derived exosomes to induce transplant tolerance. The edited pretreatment of MSCderived exosomes plays an immunomodulatory role, which is expected to become a new direction in regenerative medicine and transplantation.

\section{DOSE ISSUES AND COMMERCIAL PRODUCTION OF MSC-DERIVED EXOSOMES}

The dose dependence of MSCs and its exosomes is a difficult problem in clinical applications. At this stage, the main route of administration is intravenous injection, and most pre-clinical studies and clinical trials have used different doses. For example, one study showed that the intravenous administration of $1-3 \times$ $10^{6} / \mathrm{kg}$ units of MSCs may reverse GvHD. In malignant tumors, 4 $\times 10^{8} / \mathrm{kg}$ could inhibit tumor growth, while low doses accelerated tumor proliferation (129). In a clinical study in novel coronavirus patients with pneumonia, $15 \mathrm{~mL}$ of exosomes derived from allogeneic bone marrow mesenchymal stem cells was added to $100 \mathrm{ml}$ of normal saline, and administered intravenously $60 \mathrm{~min}$. After a single intravenous injection of exogenous bone marrow exosomes, hypoxia, cytokines and immune reconstitution storms were profound reversal, and no patients developed adverse reactions in association with the treatment (130). However, the biological role of exosomes is not yet fully understood, and we still need to pay close attention to their side effects. It is certain that MSC-derived exosomes play an immunomodulatory role, and we are confident that the research of MSC-derived exosomes will make a major breakthrough in the future.

For clinical safety, the production of MSCs for therapeutic purposes must comply with good manufacturing practices to ensure the provision of safe, repeatable and efficient products. The production of safe and reliable clinical MSCs includes multiple requirements, including tissue sources, culture methods, and quality control standards. It is now believed that exosomes have low immunogenicity and tumorigenicity. In comparison to simple MSCs, MSC-derived exosomes are well-tolerated. And they are more convenient and practical to be applied in vivo. Thus, MSC-derived exosomes have broad prospects as a therapeutic agent. It is worth noting that although MSC exosomes avoid the risks of immunogenicity and tumorigenicity that are associated with cell transplantation, there are still many problems associated with application in the clinical setting, including production standards (e.g., culture separation, cell phenotype, quantification, and positioning tracking after infusion) and the monitoring of efficacy (131). The determination of clinical indications for different diseases, especially the production of standard dosage in the field of organ transplantation, is a problem that needs to be solved urgently.

Studies have suggested that for the actual production of therapeutic exosomes, some lentiviral vectors that are currently being tested in clinical trials should be used to transform cells.

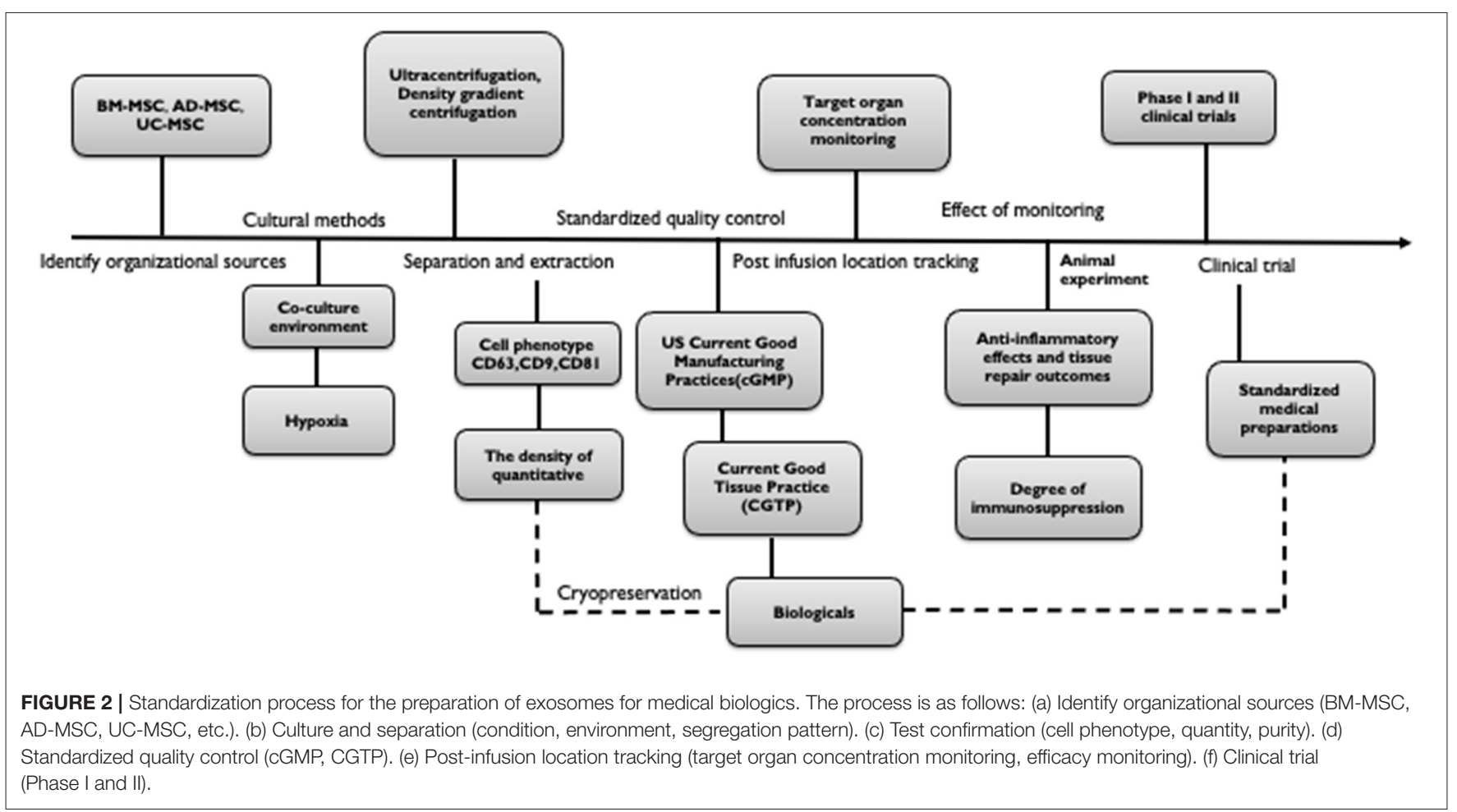


It is extremely important to establish methods that MSC-derived exosomes can be stably supplied. We not only aim to expand cell phenotypes of MSC-derived exosomes but also to pay attention to not damage the original roles of the MSC at the same time of increasing the production of exosomes. Thus, the optimization of cryopreservation strategies for the long-term storage of functional MSC-derived exosomes may be helpful for the development of off-the-shelf biologics (132). Current methods that are important for the extraction of exosomes are ultracentrifugation and density gradient centrifugation. However, methods for obtaining exosomes with high- quantity and high-purity remain a focus of research. Cytokine priming upregulated RAB27B siRNA in AD-MSCs, increasing their secretion of exosomes, which is a useful strategy for harvesting anti-inflammatory MSC-EVs for clinical applications (39). As mentioned earlier, gene editing is used to overexpress therapeutically effective molecules (such as mRNA, miRNA, and proteins) in MSCs to produce characteristic MSC-derived exosomes for different diseases. Alternatively, the therapeutic efficacy may be increased by targeting organ-targeted MSCderived exosomes. In addition to the production standards in biomedical engineering, it is equally important to verify the safety and feasibility through a large number of preclinical studies and clinical trials. The specific phenotype and function and the degree of conversion should be verified by quality control methods and should adhere to quality standards. In this section, we summarized the preparation of a standardization process for the medical application of exosomes as biologic agents (Figure 2). However, the standard has not

\section{REFERENCES}

1. Primc D, Rački S, Arnol M, Marinović M, Fućak-Primc A, Muzur A, et al. The beginnings of kidney transplantation in south-east europe. Acta Clin Croat. (2020) 59:135-40. doi: 10.20471/acc.2020.59.01.16

2. Fang YH, Wang SPH, Chang HY, Yang PJ, Liu PY, Liu YW. Immunogenicity in stem cell therapy for cardiac regeneration. Acta Cardiol Sin. (2020) 36:588-94. doi: 10.6515/ACS.202011_36(6).20200811A

3. Takayama Y, Kusamori K, Tsukimori C, Shimizu Y, Hayashi M, Kiyama I, et al. Anticancer drug-loaded mesenchymal stem cells for targeted cancer therapy. J Control Release. (2020) 329:1090-101. doi: $10.1016 /$ j.jconrel.2020.10.037

4. Sordi V. Mesenchymal stem cell homing capacity. Transplantation. (2009) 87(Suppl. 9):S42-5. doi: 10.1097/TP.0b013e3181a28533

5. Meng QS, Liu J, Wei L, Fan HM, Zhou XH, Liang XT. Senescent mesenchymal stem/stromal cells and restoring their cellular functions. World J Stem Cells. (2020) 12:966-85. doi: 10.4252/wjsc.v12.i9.966

6. Dominici M, Le Blanc K, Mueller I, Slaper-Cortenbach I, Marini F, Krause D, et al. Minimal criteria for defining multipotent mesenchymal stromal cells. The international society for cellular therapy position statement. Cytotherapy. (2006) 8:315-7. doi: 10.1080/14653240600855905

7. van Megen KM, van 't Wout ET, Lages Motta J, Dekker B, Nikolic T, Roep BO. Activated mesenchymal stromal cells process and present antigens regulating adaptive immunity. Front Immunol. (2019) 10:694. doi: 10.3389/fimmu.2019.00694

8. Fathollahi A, Hashemi SM, Haji Molla Hoseini M, Tavakoli S, Farahani E, Yeganeh F. Intranasal administration of small extracellular vesicles derived from mesenchymal stem cells ameliorated the experimental autoimmune encephalomyelitis. Int Immunopharmacol. (2020) 90:107207. doi: $10.1016 /$ j.intimp.2020.107207 yet reached a consensus. Although we have put forward some points, we still need a multi-center study to determine a feasible solution.

\section{CONCLUDING REMARKS}

We hope that MSC-derived exosomes research will open up new medical and pharmaceutical fields while focusing on safety, the standardization of production steps, and determination of therapeutic doses, providing new viable commercial products for the treatment of organ transplantation and GvHD, and other diseases.

\section{AUTHOR CONTRIBUTIONS}

QYZ, SJZ, W-ZG, and X-KL conceived and designed the manuscript. QYZ and X-KL wrote the paper. All authors listed have made a substantial, direct and intellectual contribution to the work, and approved it for publication.

\section{FUNDING}

This work was supported in part by Science and Technology Innovation Talents in Henan Universities (No. 19HASTIT003) and research grants from the National Center for Child Health and Development (30-20), the Ministry of Education, Culture, Sports, Science and Technology of Japan (17H04277, 18F17794, and $19 \mathrm{~K} 18045)$.

9. Carreras-Planella L, Monguió-Tortajada M, Borràs F E, Franquesa M. Immunomodulatory effect of MSC on B cells is independent of secreted extracellular vesicles. Front Immunol. (2019) 10:1288. doi: 10.3389/fimmu.2019.02413

10. Mittal SK, Foulsham W, Shukla S, Elbasiony E, Omoto M, Chauhan SK. Mesenchymal stromal cells modulate corneal alloimmunity via secretion of hepatocyte growth factor. Stem Cells Transl Med. (2019) 8:1030-40. doi: 10.1002/sctm.19-0004

11. Spaggiari GM, Capobianco A, Abdelrazik H, Becchetti F, Mingari MC, Moretta L. Mesenchymal stem cells inhibit natural killer-cell proliferation, cytotoxicity, and cytokine production: role of indoleamine 2,3-dioxygenase and prostaglandin E2. Blood. (2008) 111:1327-33. doi: 10.1182/blood-2007-02-074997

12. Glennie S, Soeiro I, Dyson PJ, Lam EW, Dazzi F. Bone marrow mesenchymal stem cells induce division arrest anergy of activated $\mathrm{T}$ cells. Blood. (2005) 105:2821-7. doi: 10.1182/blood-2004-093696

13. Chen J, Ji T, Wu D, Jiang S, Zhao J, Lin H, et al. Human mesenchymal stem cells promote tumor growth via MAPK pathway and metastasis by epithelial mesenchymal transition and integrin $\alpha 5$ in hepatocellular carcinoma. Cell Death Dis. (2019) 10:425. doi: 10.1038/s41419-0191622-1

14. Hoogduijn MJ, Lombardo E. Mesenchymal stromal cells anno 2019: dawn of the therapeutic era? Concise Review. Stem Cells Transl Med. (2019) 8:1126-34. doi: 10.1002/sctm.19-0073

15. Valencia J, Blanco $B$, Yáñez R, Vázquez $M$, Herrero Sánchez $C$, Fernández-García M, et al. Comparative analysis of the immunomodulatory capacities of human bone marrow- and adipose tissue-derived mesenchymal stromal cells from the same donor. Cytotherapy. (2016) 18:1297-311. doi: 10.1016/j.jcyt.2016.07.006 
16. Pelizzo G, Veschi V, Mantelli M, Croce S, Di Benedetto V, D’Angelo P, et al. Microenvironment in neuroblastoma: isolation and characterization of tumor-derived mesenchymal stromal cells. BMC Cancer. (2018) 18:1176. doi: 10.1186/s12885-018-5082-2

17. Qiu X, Liu J, Zheng C, Su Y, Bao L, Zhu B, et al. Exosomes released from educated mesenchymal stem cells accelerate cutaneous wound healing via promoting angiogenesis. Cell Prolif. (2020) 53:e12830. doi: $10.1111 /$ cpr.12830

18. Molchanova EA, Bueverova EI, Starostin VI, Domaratskaia EI. [The sensitivity of mesenchymal stromal cell subpopulations with different times of adhesion property manifestation and derived from hemopoietic organs to growth factors EGF, bFGF, and PDGF]. Izv Akad Nauk Ser Biol. (2011) 133-44.

19. Torres Crigna A, Uhlig S, Elvers-Hornung S, Klüter H, Bieback K. Human adipose tissue-derived stromal cells suppress human, but not murine lymphocyte proliferation, via indoleamine 2,3-dioxygenase activity. Cells. (2020) 9:2419. doi: 10.3390/cells9112419

20. Yang H, Sun J, Li Y, Duan WM, Bi J, Qu T. Human umbilical cord-derived mesenchymal stem cells suppress proliferation of PHAactivated lymphocytes in vitro by inducing CD4(+)CD25(high)CD45RA(+) regulatory $\mathrm{T}$ cell production and modulating cytokine secretion. Cell Immunol. (2016) 302:26-31. doi: 10.1016/j.cellimm.2016.01.002

21. Liang C, Chen SL, Wang M, Zhai WJ, Zhou Z, Pang AM, et al. [Synergistic immunomodulatory effects of interferon-gamma and bone marrow mesenchymal stem cells]. Zhonghua Xue Ye Xue Za Zhi. (2013) 34:213-6. doi: 10.3892/mmr.2017.6330

22. Cho DI, Kim MR, Jeong HY, Jeong HC, Jeong $\mathrm{MH}$, Yoon $\mathrm{SH}$, et al. Mesenchymal stem cells reciprocally regulate the M1/M2 balance in mouse bone marrow-derived macrophages. Exp Mol Med. (2014) 46:e70. doi: 10.1038/emm.2013.135

23. Vasandan AB, Jahnavi S, Shashank C, Prasad P, Kumar A, Prasanna SJ. Human Mesenchymal stem cells program macrophage plasticity by altering their metabolic status via a PGE(2)-dependent mechanism. Sci Rep. (2016) 6:38308. doi: 10.1038/srep38308

24. Phinney DG, Pittenger MF. Concise review: MSC-derived exosomes for cell-free therapy. Stem Cells. (2017) 35:851-8. doi: 10.1002/stem.2575

25. Harman RM, Patel RS, Fan JC, Park JE, Rosenberg BR, Van de Walle GR. Single-cell RNA sequencing of equine mesenchymal stromal cells from primary donor-matched tissue sources reveals functional heterogeneity in immune modulation and cell motility. Stem Cell Res Ther. (2020) 11:524. doi: 10.1186/s13287-020-02043-5

26. Galipeau J, Sensébé L. Mesenchymal stromal cells: clinical challenges and therapeutic opportunities. Cell Stem Cell. (2018) 22:824-33. doi: 10.1016/j.stem.2018.05.004

27. Eggenhofer E, Renner P, Soeder Y, Popp FC, Hoogduijn MJ, Geissler EK, et al. Features of synergism between mesenchymal stem cells and immunosuppressive drugs in a murine heart transplantation model. Transpl Immunol. (2011) 25:141-7. doi: 10.1016/j.trim.2011.06.002

28. Maccario R, Podestà M, Moretta A, Cometa A, Comoli P, Montagna D, et al. Interaction of human mesenchymal stem cells with cells involved in alloantigen-specific immune response favors the differentiation of $\mathrm{CD} 4{ }^{+} \mathrm{T}$ cell subsets expressing a regulatory/suppressive phenotype. Haematologica. (2005) 90:516-25.

29. Roefs MT, Sluijter JPG, Vader P. Extracellular vesicle-associated proteins in tissue repair. Trends Cell Biol. (2020) 30:990-1013. doi: $10.1016 /$ j.tcb.2020.09.009

30. Théry C, Ostrowski M, Segura E. Membrane vesicles as conveyors of immune responses. Nat Rev Immunol. (2009) 9:581-93. doi: 10.1038/ nri2567

31. Zhang P, Wu X, Gardashova G, Yang Y, Zhang Y, Xu L, et al. Molecular and functional extracellular vesicle analysis using nanopatterned microchips monitors tumor progression and metastasis. Sci Transl Med. (2020) 12:eaaz2878. doi: 10.1126/scitranslmed.aaz2878

32. van der Pol E, Böing AN, Harrison P, Sturk A, Nieuwland R. Classification, functions, and clinical relevance of extracellular vesicles. Pharmacol Rev. (2012) 64:676-705. doi: 10.1124/pr.112.005983

33. Pegtel DM, Gould SJ. Exosomes. Annu Rev Biochem. (2019) 88:487-514. doi: 10.1146/annurev-biochem-013118-111902
34. Barker CF, Billingham RE. The lymphatic status of hamster cheek pouch tissue in relation to its properties as a graft and as a graft site. J Exp Med. (1971) 133:620-39. doi: 10.1084/jem.133.3.620

35. Asare-Werehene M, Nakka K, Reunov A, Chiu CT, Lee WT, Abedini MR, et al. The exosome-mediated autocrine and paracrine actions of plasma gelsolin in ovarian cancer chemoresistance. Oncogene. (2020) 39:1600-16. doi: 10.1038/s41388-019-1087-9

36. Spees JL, Lee RH, Gregory CA. Mechanisms of mesenchymal stem/stromal cell function. Stem Cell Res Ther. (2016) 7:125. doi: 10.1186/s13287-016-0363-7

37. Bruno S, Kholia S, Deregibus MC, Camussi G. The role of extracellular vesicles as paracrine effectors in stem cell-based therapies. Adv Exp Med Biol. (2019) 1201:175-93. doi: 10.1007/978-3-030-31206-0_9

38. Wu K, Xing F, Wu SY, Watabe K. Extracellular vesicles as emerging targets in cancer: recent development from bench to bedside. Biochim Biophys Acta Rev Cancer. (2017) 1868:538-63. doi: 10.1016/j.bbcan.2017.10.001

39. Cheng A, Choi D, Lora M, Shum-Tim D, Rak J, Colmegna I. Human multipotent mesenchymal stromal cells cytokine priming promotes RAB27B-regulated secretion of small extracellular vesicles with immunomodulatory cargo. Stem Cell Res Ther. (2020) 11:539. doi: 10.1186/s13287-020-02050-6

40. Mead B, Tomarev S. Bone marrow-derived mesenchymal stem cellsderived exosomes promote survival of retinal ganglion cells through miRNA-dependent mechanisms. Stem Cells Transl Med. (2017) 6:1273-85. doi: $10.1002 /$ sctm.16-0428

41. Simpson RJ, Lim JW, Moritz RL, Mathivanan S. Exosomes: proteomic insights and diagnostic potential. Expert Rev Proteomics. (2009) 6:267-83. doi: 10.1586/epr.09.17

42. Andreu Z, Yáñez-Mó M. Tetraspanins in extracellular vesicle formation and function. Front Immunol. (2014) 5:442. doi: 10.3389/fimmu.2014.00442

43. He C, Zheng S, Luo Y, Wang B. Exosome theranostics: biology and translational medicine. Theranostics. (2018) 8:237-55. doi: 10.7150/thno.21945

44. Kahroba H, Hejazi M S, Samadi N. Exosomes: from carcinogenesis and metastasis to diagnosis and treatment of gastric cancer. Cell Mol Life Sci. (2019) 76:1747-58. doi: 10.1007/s00018-019-03035-2

45. Min BH, Shin JS, Kim JM, Kang SJ, Kim HJ, Yoon IH, et al. Delayed revascularization of islets after transplantation by IL- 6 blockade in pig to non-human primate islet xenotransplantation model. Xenotransplantation. (2018) 25. doi: 10.1111/xen.12374

46. Katsuda T, Tsuchiya R, Kosaka N, Yoshioka Y, Takagaki K, Oki K, et al. Human adipose tissue-derived mesenchymal stem cells secrete functional neprilysin-bound exosomes. Sci Rep. (2013) 3:1197. doi: 10.1038/srep01197

47. Dostert G, Mesure B, Menu P, Velot É. How do mesenchymal stem cells influence or are influenced by microenvironment through extracellular vesicles communication? Front Cell Dev Biol. (2017) 5:6. doi: 10.3389/fcell.2017.00006

48. Whiteside TL. Exosome and mesenchymal stem cell cross-talk in the tumor microenvironment. Semin Immunol. (2018) 35:69-79. doi: 10.1016/j.smim.2017.12.003

49. Nie W, Ma X, Yang $\mathrm{C}$, Chen $\mathrm{Z}$, Rong $\mathrm{P}, \mathrm{Wu} \mathrm{M}$, et al. Human mesenchymal-stem-cells-derived exosomes are important in enhancing porcine islet resistance to hypoxia. Xenotransplantation. (2018) 25:e12405. doi: 10.1111/xen.12405

50. Du YM, Zhuansun YX, Chen R, Lin L, Lin Y, Li JG. Mesenchymal stem cell exosomes promote immunosuppression of regulatory $\mathrm{T}$ cells in asthma. Exp Cell Res. (2018) 363:114-20. doi: 10.1016/j.yexcr.2017.12.021

51. Riazifar M, Mohammadi MR, Pone EJ, Yeri A, Lässer C, Segaliny AI, et al. Stem cell-derived exosomes as nanotherapeutics for autoimmune and neurodegenerative disorders. ACS Nano. (2019) 13:6670-88. doi: 10.1021/acsnano.9b01004

52. Askenase PW. COVID-19 therapy with mesenchymal stromal cells (MSC) and convalescent plasma must consider exosome involvement: do the exosomes in convalescent plasma antagonize the weak immune antibodies? J Extracell Vesicles. (2020) 10:e12004. doi: 10.1002/jev2.12004

53. Bulati M, Miceli V, Gallo A, Amico G, Carcione C, Pampalone M, et al. The immunomodulatory properties of the human amnion-derived mesenchymal stromal/stem cells are induced by INF- $\gamma$ produced by activated 
lymphomonocytes and are mediated by cell-to-cell contact and soluble factors. Front Immunol. (2020) 11:54. doi: 10.3389/fimmu.2020.00054

54. Zhang Q, Fu L, Liang Y, Guo Z, Wang L, Ma C, et al. Exosomes originating from MSCs stimulated with TGF- $\beta$ and IFN- $\gamma$ promote Treg differentiation. J Cell Physiol. (2018) 233:6832-40. doi: 10.1002/jcp.26436

55. Long X, Yao X, Jiang Q, Yang Y, He X, Tian W, et al. Astrocytederived exosomes enriched with miR-873a-5p inhibit neuroinflammation via microglia phenotype modulation after traumatic brain injury. $J$ Neuroinflammation. (2020) 17:89. doi: 10.1186/s12974-020-01761-0

56. Wang X, Yan X, Zhang L, Cai J, Zhou Y, Liu H, et al. Identification and peptidomic profiling of exosomes in preterm human milk: insights into necrotizing enterocolitis prevention. Mol Nutr Food Res. (2019) e1801247. doi: 10.1002/mnfr.201801247. [Epub ahead of print].

57. Li B, Hock A, Wu RY, Minich A, Botts SR, Lee C, et al. Bovine milkderived exosomes enhance goblet cell activity and prevent the development of experimental necrotizing enterocolitis. PLoS ONE. (2019) 14:e0211431. doi: 10.1371/journal.pone.0211431

58. Chen W, Wang X, Yan X, Yu Z, Zhang J, Han S. The emerging role of exosomes in the pathogenesis, prognosis and treatment of necrotizing enterocolitis. Am J Transl Res. (2020) 12:7020-33.

59. Porzionato A, Zaramella P, Dedja A, Guidolin D, Van Wemmel K, Macchi $\mathrm{V}$, et al. Intratracheal administration of clinical-grade mesenchymal stem cell-derived extracellular vesicles reduces lung injury in a rat model of bronchopulmonary dysplasia. Am J Physiol Lung Cell Mol Physiol. (2019) 316:L6-19. doi: 10.1152/ajplung.00109.2018

60. Braun R K, Chetty C, Balasubramaniam V, Centanni R, Haraldsdottir K, Hematti P, et al. Intraperitoneal injection of MSC-derived exosomes prevent experimental bronchopulmonary dysplasia. Biochem Biophys Res Commun. (2018) 503:2653-8. doi: 10.1016/j.bbrc.2018.08.019

61. Willis GR, Fernandez-Gonzalez A, Anastas J, Vitali SH, Liu X, Ericsson $\mathrm{M}$, et al. Mesenchymal stromal cell exosomes ameliorate experimental bronchopulmonary dysplasia and restore lung function through macrophage immunomodulation. Am J Respir Crit Care Med. (2018) 197:104-16. doi: 10.1164/rccm.201705-0925OC

62. Thomi G, Surbek D, Haesler V, Joerger-Messerli M, Schoeberlein A. Exosomes derived from umbilical cord mesenchymal stem cells reduce microglia-mediated neuroinflammation in perinatal brain injury. Stem Cell Res Ther. (2019) 10:105. doi: 10.1186/s13287-019-1207-z

63. Xing L, Tang X, Wu K, Huang X, Yi Y, Huan J. LncRNA HAND2AS1 suppressed the growth of triple negative breast cancer via reducing secretion of MSCs derived exosomal miR-106a-5p. Aging. (2020) 13:424-36. doi: 10.18632/aging.202148

64. Xin H, Li Y, Buller B, Katakowski M, Zhang Y, Wang X, et al. Exosomemediated transfer of miR-133b from multipotent mesenchymal stromal cells to neural cells contributes to neurite outgrowth. Stem Cells. (2012) 30:1556-64. doi: 10.1002/stem.1129

65. Shen $\mathrm{H}$, Yao X, Li H, Li X, Zhang $\mathrm{T}$, Sun $\mathrm{Q}$, et al. Role of exosomes derived from miR-133b modified MSCs in an experimental rat model of intracerebral hemorrhage. J Mol Neurosci. (2018) 64:421-30. doi: 10.1007/s12031-018-1041-2

66. Li D, Zhang P, Yao X, Li H, Shen H, Li X, et al. Exosomes derived from miR133b-modified mesenchymal stem cells promote recovery after spinal cord injury. Front Neurosci. (2018) 12:845. doi: 10.3389/fnins.2018.00845

67. Ma J, Zhao Y, Sun L, Sun X, Zhao X, Sun X, et al. Exosomes derived from akt-modified human umbilical cord mesenchymal stem cells improve cardiac regeneration and promote angiogenesis via activating platelet-derived growth factor D. Stem Cells Transl Med. (2017) 6:51-9. doi: $10.5966 / \mathrm{sctm} .2016-0038$

68. Huang L, Yang L, Ding Y, Jiang X, Xia Z, You Z. Human umbilical cord mesenchymal stem cells-derived exosomes transfers microRNA-19a to protect cardiomyocytes from acute myocardial infarction by targeting SOX6. Cell Cycle. (2020) 19:339-53. doi: 10.1080/15384101.2019.1711305

69. Tang J, Jin L, Liu Y, Li L, Ma Y, Lu L, et al. Exosomes derived from mesenchymal stem cells protect the myocardium against ischemia/reperfusion injury through inhibiting pyroptosis. Drug Des Devel Ther. (2020) 14:3765-75. doi: 10.2147/DDDT.S239546

70. Jiang W, Tan Y, Cai M, Zhao T, Mao F, Zhang X, et al. Human umbilical cord MSC-derived exosomes suppress the development of $\mathrm{CCl}(4)$-induced liver injury through antioxidant effect. Stem Cells Int. (2018) 2018:6079642. doi: $10.1155 / 2018 / 6079642$

71. Levy O, Kuai R, Siren EMJ, Bhere D, Milton Y, Nissar N, et al. Shattering barriers toward clinically meaningful MSC therapies. Sci Adv. (2020) 6:eaba6884. doi: 10.1126/sciadv.aba6884

72. Monguió-Tortajada $\mathrm{M}, \quad$ Lauzurica-Valdemoros $\mathrm{R}$, Borràs FE. Tolerance in organ transplantation: from conventional immunosuppression to extracellular vesicles. Front Immunol. (2014) 5:416. doi: $10.3389 /$ fimmu.2014.00416

73. Stepkowski SM, Raza-Ahmad A, Duncan WR. The role of class I and class II MHC antigens in the rejection of vascularized heart allografts in mice. Transplantation. (1987) 44:753-9. doi: 10.1097/00007890-198712000-00006

74. Pêche H, Renaudin K, Beriou G, Merieau E, Amigorena S, Cuturi MC. Induction of tolerance by exosomes and short-term immunosuppression in a fully MHC-mismatched rat cardiac allograft model. Am J Transplant. (2006) 6:1541-50. doi: 10.1111/j.1600-6143.2006.01344.x

75. Pêche H, Heslan M, Usal C, Amigorena S, Cuturi M C. Presentation of donor major histocompatibility complex antigens by bone marrow dendritic cell-derived exosomes modulates allograft rejection. Transplantation. (2003) 76:1503-10. doi: 10.1097/01.TP.0000092494.75313.38

76. Li X, Li JJ, Yang JY, Wang DS, Zhao W, Song WJ, et al. Tolerance induction by exosomes from immature dendritic cells and rapamycin in a mouse cardiac allograft model. PLoS ONE. (2012) 7:e44045. doi: 10.1371/journal.pone.0044045

77. Yang X, Meng S, Jiang $\mathrm{H}$, Zhu C, Wu W. Exosomes derived from immature bone marrow dendritic cells induce tolerogenicity of intestinal transplantation in rats. J Surg Res. (2011) 171:826-32. doi: $10.1016 /$ j.jss.2010.05.021

78. Ma B, Yang JY, Song WJ, Ding R, Zhang ZC, Ji HC, et al. Combining exosomes derived from immature dcs with donor antigen-specific Treg cells induces tolerance in a rat liver allograft model. Sci Rep. (2016) 6:32971. doi: $10.1038 /$ srep32971

79. Gregorini M, Corradetti V, Pattonieri EF, Rocca C, Milanesi S, Peloso A, et al. Perfusion of isolated rat kidney with mesenchymal stromal cells/extracellular vesicles prevents ischaemic injury. J Cell Mol Med. (2017) 21:3381-93. doi: $10.1111 / j \mathrm{cmm} .13249$

80. Chouchani ET, Pell VR, Gaude E, Aksentijević D, Sundier SY, Robb EL, et al. Ischaemic accumulation of succinate controls reperfusion injury through mitochondrial ROS. Nature. (2014) 515:431-5. doi: 10.1038/nature 13909

81. Rigo F, De Stefano N, Navarro-Tableros V, David E, Rizza G, Catalano $\mathrm{G}$, et al. Extracellular vesicles from human liver stem cells reduce injury in an ex vivo normothermic hypoxic rat liver perfusion model. Transplantation. (2018) 102:e205-10. doi: 10.1097/TP.00000000000 02123

82. Stone ML, Zhao Y, Robert Smith J, Weiss ML, Kron I L, Laubach VE, et al. Mesenchymal stromal cell-derived extracellular vesicles attenuate lung ischemia-reperfusion injury and enhance reconditioning of donor lungs after circulatory death. Respir Res. (2017) 18:212. doi: 10.1186/s12931-017-0704-9

83. Zhao J, Li X, Hu J, Chen F, Qiao S, Sun X, et al. Mesenchymal stromal cell-derived exosomes attenuate myocardial ischaemia-reperfusion injury through miR-182-regulated macrophage polarization. Cardiovasc Res. (2019) 115:1205-16. doi: 10.1093/cvr/cvz040

84. Wang R, Lin M, Li L, Li L, Qi G, Rong R, et al. [Bone marrow mesenchymal stem cell-derived exosome protects kidney against ischemia reperfusion injury in rats]. Zhonghua Yi Xue Za Zhi. (2014) 94:3298-303.

85. Zhang L, Song Y, Chen L, Li D, Feng H, Lu Z, et al. MiR-20acontaining exosomes from umbilical cord mesenchymal stem cells alleviates liver ischemia/reperfusion injury. J Cell Physiol. (2020) 235:3698-710. doi: $10.1002 /$ jcp. 29264

86. Yang B, Duan W, Wei L, Zhao Y, Han Z, Wang J, et al. Bone marrow mesenchymal stem cell-derived hepatocyte-like cell exosomes reduce hepatic ischemia/reperfusion injury by enhancing autophagy. Stem Cells Dev. (2020) 29:372-9. doi: 10.1089/scd.2019.0194

87. Liu J, Chen T, Lei P, Tang X, Huang P. Exosomes released by bone marrow mesenchymal stem cells attenuate lung injury induced by intestinal ischemia reperfusion via the TLR4/NF-кB pathway. Int J Med Sci. (2019) 16:1238-44. doi: $10.7150 /$ ijms.35369 
88. Benichou G, Wang M, Ahrens K, Madsen JC. Extracellular vesicles in allograft rejection and tolerance. Cell Immunol. (2020) 349:104063. doi: 10.1016/j.cellimm.2020.104063

89. Schröppel B, Legendre C. Delayed kidney graft function: from mechanism to translation. Kidney Int. (2014) 86:251-8. doi: 10.1038/ki.2014.18

90. Kennel PJ, Saha A, Maldonado DA, Givens R, Brunjes DL, Castillero E, et al. Serum exosomal protein profiling for the non-invasive detection of cardiac allograft rejection. J Heart Lung Transplant. (2018) 37:409-17. doi: 10.1016/j.healun.2017.07.012

91. Ono Y, Perez-Gutierrez A, Nakao T, Dai H, Camirand G, Yoshida O, et al. Graft-infiltrating PD-L1(hi) cross-dressed dendritic cells regulate antidonor $\mathrm{T}$ cell responses in mouse liver transplant tolerance. Hepatology. (2018) 67:1499-515. doi: 10.1002/hep.29529

92. Vallabhajosyula P, Korutla L, Habertheuer A, Yu M, Rostami S, Yuan CX, et al. Tissue-specific exosome biomarkers for noninvasively monitoring immunologic rejection of transplanted tissue. J Clin Invest. (2017) 127:137591. doi: $10.1172 /$ JCI87993

93. Gunasekaran $M$, Sharma $M$, Hachem $R$, Bremner $R$, Smith MA, Mohanakumar T. Circulating exosomes with distinct properties during chronic lung allograft rejection. J Immunol. (2018) 200:2535-41. doi: 10.4049/jimmunol.1701587

94. Wang M, Yan L, Li Q, Yang Y, Turrentine M, March K, et al. Mesenchymal stem cell secretions improve donor heart function following ex vivo cold storage. J Thorac Cardiovasc Surg. (2020) S0022-5223(20)32487-9. doi: 10.1016/j.jtcvs.2020.08.095

95. Charles CJ, Li RR, Yeung T, Mazlan SMI, Lai RC, de Kleijn DPV, et al. Systemic mesenchymal stem cell-derived exosomes reduce myocardial infarct size: characterization with MRI in a porcine model. Front Cardiovasc Med. (2020) 7:601990. doi: 10.3389/fcvm.2020.601990

96. Yan Y, Jiang W, Tan Y, Zou S, Zhang H, Mao F, et al. hucMSC exosomederived GPX1 is required for the recovery of hepatic oxidant injury. Mol Ther. (2017) 25:465-79. doi: 10.1016/j.ymthe.2016.11.019

97. He JG, Xie Q L, Li BB, Zhou L, Yan D. Exosomes derived from IDO1-overexpressing rat bone marrow mesenchymal stem cells promote immunotolerance of cardiac allografts. Cell Transplant. (2018) 27:1657-83. doi: 10.1177/0963689718805375

98. Baek G, Choi H, Kim Y, Lee HC, Choi C. Mesenchymal stem cell-derived extracellular vesicles as therapeutics and as a drug delivery platform. Stem Cells Transl Med. (2019) 8:880-6. doi: 10.1002/sctm.18-0226

99. Khalife J, Sanchez JF, Pichiorri F. Extracellular vesicles in hematological malignancies: from biomarkers to therapeutic tools. Diagnostics. (2020) 10:1065. doi: 10.3390/diagnostics10121065

100. Ganji A, Farahani I, Shojapour M, Ghazavi A, Mosayebi G. In vivo therapeutic effects of colorectal cancer cell-derived exosomes. Iran J Basic Med Sci. (2020) 23:1439-44. doi: 10.22038/ijbms.2020.46465.10730

101. Lou G, Song X, Yang F, Wu S, Wang J, Chen Z, et al. Exosomes derived from miR-122-modified adipose tissue-derived MSCs increase chemosensitivity of hepatocellular carcinoma. J Hematol Oncol. (2015) 8:122. doi: 10.1186/s13045-015-0220-7

102. Lou G, Chen L, Xia C, Wang W, Qi J, Li A, et al. MiR-199a-modified exosomes from adipose tissue-derived mesenchymal stem cells improve hepatocellular carcinoma chemosensitivity through mTOR pathway. J Exp Clin Cancer Res. (2020) 39:4. doi: 10.1186/s13046-019-1512-5

103. Mendt M, Rezvani K, Shpall E. Mesenchymal stem cell-derived exosomes for clinical use. Bone Marrow Transplant. (2019) 54(Suppl. 2):789-92. doi: 10.1038/s41409-019-0616-z

104. Grange C, Bellucci L, Bussolati B, Ranghino A. Potential applications of extracellular vesicles in solid organ transplantation. Cells. (2020) 9:369. doi: $10.3390 /$ cells 9020369

105. Massa M, Croce S, Campanelli R, Abbà C, Lenta E, Valsecchi C, et al. Clinical applications of mesenchymal stem/stromal cell derived extracellular vesicles: therapeutic potential of an acellular product. Diagnostics. (2020) 10:999. doi: 10.3390/diagnostics10120999

106. Williams AM, Dennahy IS, Bhatti UF, Halaweish I, Xiong Y, Chang P, et al. Mesenchymal stem cell-derived exosomes provide neuroprotection and improve long-term neurologic outcomes in a swine model of traumatic brain injury and hemorrhagic shock. J Neurotrauma. (2019) 36:54-60. doi: $10.1089 /$ neu.2018.5711
107. Williams AM, Bhatti UF, Brown JF, Biesterveld BE, Kathawate RG, Graham NJ, et al. Early single-dose treatment with exosomes provides neuroprotection and improves blood-brain barrier integrity in swine model of traumatic brain injury and hemorrhagic shock. J Trauma Acute Care Surg. (2020) 88:207-18. doi: 10.1097/TA.0000000000002563

108. Williams AM, Wu Z, Bhatti UF, Biesterveld BE, Kemp MT, Wakam GK, et al. Early single-dose exosome treatment improves neurologic outcomes in a 7-day swine model of traumatic brain injury and hemorrhagic shock. J Trauma Acute Care Surg. (2020) 89:388-96. doi: 10.1097/TA.0000000000002698

109. Poncelet AJ, Vercruysse J, Saliez A, Gianello P. Although pig allogeneic mesenchymal stem cells are not immunogenic in vitro, intracardiac injection elicits an immune response in vivo. Transplantation. (2007) 83:783-90. doi: 10.1097/01.tp.0000258649.23081.a3

110. Kuo YR, Goto S, Shih HS, Wang FS, Lin CC, Wang CT, et al. Mesenchymal stem cells prolong composite tissue allotransplant survival in a swine model. Transplantation. (2009) 87:1769-77. doi: 10.1097/TP.0b013e3181a664f1

111. Cooper DKC, Gaston R, Eckhoff D, Ladowski J, Yamamoto T, Wang L, et al. Xenotransplantation-the current status and prospects. Br Med Bull. (2018) 125:5-14. doi: 10.1093/bmb/ldx043

112. Le Blanc K, Rasmusson I, Sundberg B, Götherström C, Hassan M, Uzunel $\mathrm{M}$, et al. Treatment of severe acute graft-versus-host disease with third party haploidentical mesenchymal stem cells. Lancet. (2004) 363:1439-41. doi: 10.1016/S0140-6736(04)16104-7

113. Goto T, Murata M, Nishida T, Terakura S, Kamoshita S, Ishikawa Y, et al. Phase I clinical trial of intra-bone marrow cotransplantation of mesenchymal stem cells in cord blood transplantation. Stem Cells Transl Med. (2020). doi: 10.1002/sctm.20-0381. [Epub ahead of print].

114. Goto T, Murata M, Terakura S, Nishida T, Adachi Y, Ushijima Y, et al. Phase I study of cord blood transplantation with intrabone marrow injection of mesenchymal stem cells: a clinical study protocol. Medicine. (2018) 97:e0449. doi: 10.1097/MD.0000000000010449

115. Jurado M, De La Mata C, Ruiz-García A, López-Fernández E, Espinosa $\mathrm{O}$, Remigia MJ, et al. Adipose tissue-derived mesenchymal stromal cells as part of therapy for chronic graft-versus-host disease: a phase I/II study. Cytotherapy. (2017) 19:927-36. doi: 10.1016/j.jcyt.2017.05.002

116. Zhou L, Liu S, Wang Z, Yao J, Cao W, Chen S, et al. Bone marrow-derived mesenchymal stem cells modified with Akt1 ameliorates acute liver GVHD. Biol Proced Online. (2019) 21:24. doi: 10.1186/s12575-019-0112-2

117. Dotoli GM, De Santis GC, Orellana MD, de Lima Prata K, Caruso SR, Fernandes TR, et al. Mesenchymal stromal cell infusion to treat steroidrefractory acute GvHD III/IV after hematopoietic stem cell transplantation. Bone Marrow Transplant. (2017) 52:859-62. doi: 10.1038/bmt.2017.35

118. Zhao L, Chen S, Yang P, Cao H, Li L. The role of mesenchymal stem cells in hematopoietic stem cell transplantation: prevention and treatment of graft-versus-host disease. Stem Cell Res Ther. (2019) 10:182. doi: 10.1186/s13287-019-1287-9

119. Kordelas L, Rebmann V, Ludwig AK, Radtke S, Ruesing J, Doeppner TR, et al. MSC-derived exosomes: a novel tool to treat therapy-refractory graft-versushost disease. Leukemia. (2014) 28:970-3. doi: 10.1038/leu.2014.41

120. Lai P, Chen X, Guo L, Wang Y, Liu X, Liu Y, et al. A potent immunomodulatory role of exosomes derived from mesenchymal stromal cells in preventing cGVHD. J Hematol Oncol. (2018) 11:135. doi: 10.1186/s13045-018-0680-7

121. Zhang B, Yeo RWY, Lai RC, Sim EWK, Chin KC, Lim SK. Mesenchymal stromal cell exosome-enhanced regulatory T-cell production through an antigen-presenting cell-mediated pathway. Cytotherapy. (2018) 20:687-96. doi: 10.1016/j.jcyt.2018.02.372

122. Guo L, Lai P, Wang Y, Huang T, Chen X, Geng S, et al. Extracellular vesicles derived from mesenchymal stem cells prevent skin fibrosis in the cGVHD mouse model by suppressing the activation of macrophages and B cells immune response. Int Immunopharmacol. (2020) 84:106541. doi: 10.1016/j.intimp.2020.106541

123. Fujii S, Miura Y, Fujishiro A, Shindo T, Shimazu Y, Hirai H, et al. Graftversus-host disease amelioration by human bone marrow mesenchymal stromal/stem cell-derived extracellular vesicles is associated with peripheral preservation of naive T cell populations. Stem Cells. (2018) 36:434-45. doi: $10.1002 /$ stem.2759 
124. Shao J, Zaro J, Shen Y. Advances in exosome-based drug delivery and tumor targeting: from tissue distribution to intracellular fate. Int J Nanomedicine. (2020) 15:9355-71. doi: 10.2147/IJN.S281890

125. Xu L, Faruqu FN, Liam-Or R, Abu Abed O, Li D, Venner K, et al. Design of experiment (DoE)-driven in vitro and in vivo uptake studies of exosomes for pancreatic cancer delivery enabled by copper-free click chemistry-based labelling. J Extracell Vesicles. (2020) 9:1779458. doi: $10.1080 / 20013078.2020 .1779458$

126. Kadle RL, Abdou SA, Villarreal-Ponce AP, Soares MA, Sultan DL, David JA, et al. Microenvironmental cues enhance mesenchymal stem cell-mediated immunomodulation and regulatory T-cell expansion. PLOS ONE. (2018) 13:e0193178. doi: 10.1371/journal.pone.0193178

127. Wen D, Peng Y, Liu D, Weizmann Y, Mahato RI. Mesenchymal stem cell and derived exosome as small RNA carrier and immunomodulator to improve islet transplantation. J Control Release. (2016) 238:166-75. doi: 10.1016/j.jconrel.2016.07.044

128. Marote A, Teixeira FG, Mendes-Pinheiro B, Salgado AJ. MSCs-derived exosomes: cell-secreted nanovesicles with regenerative potential. Front Pharmacol. (2016) 7:231. doi: 10.3389/fphar.2016.00231

129. Ra JC, Shin IS, Kim SH, Kang SK, Kang BC, Lee HY, et al. Safety of intravenous infusion of human adipose tissue-derived mesenchymal stem cells in animals and humans. Stem Cells Dev. (2011) 20:1297-308. doi: $10.1089 /$ scd.2010.0466
130. Sengupta V, Sengupta S, Lazo A, Woods P, Nolan A, Bremer N. Exosomes derived from bone marrow mesenchymal stem cells as treatment for severe COVID-19. Stem Cells Dev. (2020) 29:747-54. doi: 10.1089/scd. 2020.0080

131. Hettich BF, Ben-Yehuda Greenwald M, Werner S, Leroux JC. Exosomes for wound healing: purification optimization and identification of bioactive components. Adv Sci. (2020) 7:2002596. doi: 10.1002/advs.202002596

132. Budgude P, Kale V, Vaidya A. Cryopreservation of mesenchymal stromal cell-derived extracellular vesicles using trehalose maintains their ability to expand hematopoietic stem cells in vitro. Cryobiology. (2020) 98:152-63. doi: 10.1016/j.cryobiol.2020.11.009

Conflict of Interest: The authors declare that the research was conducted in the absence of any commercial or financial relationships that could be construed as a potential conflict of interest.

Copyright () 2021 Zheng, Zhang, Guo and Li. This is an open-access article distributed under the terms of the Creative Commons Attribution License (CC BY).

The use, distribution or reproduction in other forums is permitted, provided the original author(s) and the copyright owner(s) are credited and that the original publication in this journal is cited, in accordance with accepted academic practice. No use, distribution or reproduction is permitted which does not comply with these terms. 